\title{
Models d'ensenyament en la iniciació esportiva i l'esport escolar. Estudi comparatiu en judo
}

\author{
Teaching Models for Giving an Introduction to Sport and School Sports: \\ Comparative Study in Judo
}

JOSÉ MIGUEL ÁLAMO MENDOZA FERNANDO AMADOR RAMÍREZ

Universidad de Las Palmas de Gran Canaria

\section{XURXO DOPICO CALVO ELISEO IGLESIAS SOLER}

Universidad de A Coruña

BÁRBARA QUINTANA LIMA

Universidad de Las Palmas de Gran Canaria (Doctoranda)
Autor per a la correspondència José Miguel Álamo Mendoza jalamo@def.ulpgc.es

\section{Resum}

En aquest treball pretenem comparar tres models d'ensenyament entre si en la iniciació esportiva al judo. Els tres models d'ensenyament són el tecnicotradicional (tècnic), el model vertical amb especial incidència en la tècnica (tecnicotàctic) i el vertical estructural (tàctic). Per aquest motiu, s'han organitzat tres grups d'alumnat amb el qual s'ha desenvolupat un procés d'iniciació al judo durant quatre mesos utilitzant els mètodes d'ensenyament esmentats. En els resultats d'aquest estudi, podem comprovar que hi ha models d'ensenyament que poden resultar més adequats per a l'adquisició d'aprenentatges en la iniciació al judo.

Paraules clau: models d'ensenyament, estils d'ensenyament, esport escolar, judo

\begin{abstract}
Teaching Models for Giving an Introduction to Sport and School Sports: Comparative Study in Judo

In this paper we compare three models of introductory teaching of the sport of judo. The three teaching models are the traditional technique (Technique), the vertical model with special emphasis on technique (Technique - Tactics) and the vertical structure (Tactics). To this end, three groups of students were organized who were given a beginners' course in judo for four months using the teaching methods referred to above. The results of this study show that some teaching models may be more appropriate than others for the acquisition of knowledge in an introduction to judo.
\end{abstract}

Keywords: teaching models, teaching styles, school sport, judo

\section{Introducció}

Aquest article és el resultat d'una part del treball d'investigació que tracta de saber l'efectivitat que tenen diferents models d'ensenyament en la iniciació esportiva en un esport de lluita.

És evident que cada esport té les seves especificitats en el complex procés d'ensenyament-aprenentatge esportiu i hem optat en aquesta ocasió pel judo.

El primerenc abandonament de la pràctica espor- tiva presenta diverses i variades causes, que, més tard o més d'hora, condueixen quasi inevitablement al sedentarisme. En aquest context, s'explicaria, per exemple, el debat d'algunes dades que estem coneixent que fan referència a les taxes d'obesitat infantil (Serra et al., 2003; Contreras, 2007a), l'abandonament prematur de la pràctica esportiva juvenil (Cecchini, Echevarría, \& Méndez, 2003) i els nivells de pràctica esportiva en edat escolar (Hernández \& 
Martínez, 2007), cosa que convida a reflexionar, una vegada més, sobre la importància que ha de tenir un eficient procés d'ensenyament-aprenentatge esportiu, generador, si és possible, d'hàbits de vida saludable (Aranceta, Pérez, Ribas, \& Serra, 2005), en els quals la pràctica d'activitat física i esportiva és bàsica.

Per aconseguir l'èxit en l'ensenyament esportiu i que els alumnes se sentin competents en l'activitat que desenvolupen és important la manera com es desenvolupen els continguts. En la iniciació esportiva com a procés educatiu és prioritari estructurar les tasques amb un ambient lúdic. Gaudir amb l'activitat motiva a iniciar-se i continuar en la pràctica de l'esport. El sentiment de satisfacció i d'escàs avorriment produeix amb més probabilitats la implicació enèrgica i l'adhesió a la pràctica esportiva. La diversió s'experimenta quan es percep la millora personal amb sensació de competència i presa de consciència de la progressió en l'aprenentatge (Cecchini-Estrada, Méndez, \& Contreras, 2005; Monteagudo, 2000).

Encara que aquests aspectes formin part del conjunt del nostre projecte d'investigació, en aquest treball concretem la part que fa referència a la determinació de la metodologia d'ensenyament més eficaç de les que han estat aplicades en la investigació.

\section{Objectius de la investigació}

L'estudi, en el seu conjunt, té tres fases. En la primera, s'aplica un qüestionari inicial, en què s'estipula el nivell inicial dels alumnes en aquest esport. En la segona, que correspon al disseny experimental, es produeix el procés d'ensenyament, amb l'aplicació dels tres models d'ensenyament. I, en la tercera, en què els alumnes responen a un altre qüestionari d'escala Likert, es coneix si l'aprenentatge es va realitzar en un ambient lúdic, si van gaudir de l'activitat, si van tenir més moments de satisfacció que d'avorriment, si són conscients de la seva progressió en l'aprenentatge i si

\begin{tabular}{lrrr|l} 
Subjectes & Grup A & Grup B & Grup C & 4 \\
Homes & 36 & 30 & 20 & Taula 1 \\
Dones & 2 & 4 & 14 & $\begin{array}{l}\text { Grups i distribució } \\
\text { per sexes de la } \\
\text { Total }\end{array}$ \\
\hline
\end{tabular}

els continguts es corresponen amb les seves necessitats i expectatives.

La part de l'estudi que correspon a aquest document té com a objectiu general determinar si l'aplicació d'un o altre model d'ensenyament propicien que es produeixin millores o resultats en l'aprenentatge.

\section{Subjectes i mètode Mostra}

Van participar en aquest estudi un total de cent sis alumnes de la facultat de Ciències de l'Activitat Física i de l'Esport de la Universitat de Las Palmas de Gran Canaria, que formen part dels tres grups de pràctiques que s'organitzen de manera aleatòria per cognoms. Els alumnes estan matriculats en l'assignatura fonaments del judo de la llicenciatura en Ciències de l'Activitat Física i de l'Esport. És una matèria de caràcter troncal de segon curs amb sis crèdits, dels quals cinc són pràctics i un és teòric.

\section{Qüestionari inicial}

El nivell inicial dels alumnes en aquest esport es determina amb un qüestionari en el qual es valoren diferents aspectes relacionats:

a) Si ha practicat alguna vegada algun esport de lluita.

b) En cas afirmatiu quin d'ells.

c) Si sap en què consisteix el judo.

Els resultats referits als apartats $a$ i $b$ són els que s'expressen en les taules 2,3 i 4 .

\begin{tabular}{|c|c|c|c|c|c|c|c|c|}
\hline Esport & Freqüència & Percentatge & Esport & Freqüència & Percentatge & Esport & Freqüència & Percentatge \\
\hline Cap & 6 & 33,3 & Cap & 13 & 72,2 & Cap & 11 & 55 \\
\hline Judo & 3 & 16,7 & Karate & 1 & 5,6 & Karate & 3 & 15 \\
\hline Karate & 2 & 11,1 & Taekwondo & 2 & 11,1 & Taekwondo & 2 & 10 \\
\hline Taekwondo & 4 & 22,2 & Lluita canària & 1 & 5,6 & Lluita canària & 3 & 15 \\
\hline Lluita & 3 & 16,7 & Altres & 1 & 5,6 & Altres & 1 & 5 \\
\hline Total & 18 & 100 & Total & 18 & 100 & Total & 20 & 100 \\
\hline $\begin{array}{l}\text { aula } 2 \\
\text { Jivell inicial de }\end{array}$ & alumnes (G & & $\begin{array}{l}\text { aula } 3 \\
\text { livell inicial dels }\end{array}$ & umnes (Gru & & $\begin{array}{l}\text { aula } 4 \\
\text { ivell inicial dels }\end{array}$ & umnes (Grup & \\
\hline
\end{tabular}




\begin{tabular}{|c|c|c|c|}
\hline & \multirow{2}{*}{\multicolumn{2}{|c|}{ Model d' ensenyament }} & \multirow[b]{2}{*}{ Estil d'ensenyament } \\
\hline & & & \\
\hline & Grup A & $\begin{array}{l}\text { Vertical amb referència a la tècnica } \\
\text { Model } 1\end{array}$ & Descobriment guiat \\
\hline$\triangleright$ & Grup B & $\begin{array}{l}\text { Vertical estructural } \\
\text { Model } 2\end{array}$ & Resolució de problemes \\
\hline Models, estils d'ensenyament $\mathrm{i}$ grups & Grup C & $\begin{array}{l}\text { Tecnicotradicional } \\
\text { Model } 3\end{array}$ & Comandament directe \\
\hline
\end{tabular}

\section{Disseny experimental}

Els continguts els dividirem en dues parts (Álamo, 2008). La primera és la que dedicarem als fets $i$ conceptes,${ }^{1}$ és a dir, a aquell conjunt de principis específics que l'alumne necessitarà per al seu procés d'aprenentatge com per exemple: el reglament, les formes de caure, els desequilibris, les maneres d'agafar, els desplaçaments i les posicions.

La segona part dels continguts són els referits als procediments, ${ }^{2}$ habilitats i destreses motrius del judo com a activitat física i esportiva. Per impartir aquests continguts es van seleccionar tres models, cada un amb un estil d'ensenyament diferent. Així, cada grup d'alumnes queda associat a un model i un estil d'ensenyament. Els grups amb el model i estil d'ensenyament aplicat s'exposen en la taula 5 .
Es van impartir tots els continguts durant el segon quadrimestre del curs 2007-2008, entre febrer i juny, en els horaris de classes establerts i amb el temari previst segons el pla docent corresponent. Els dies en els quals s'impartien les classes van ser els dilluns, els dijous i els divendres, amb dues sessions pràctiques d'hora i mitja per cada grup per setmana. El nombre de sessions que van rebre els alumnes de cada grup va ser de setze. Les classes consistien en un escalfament previ, treball dels aspectes tècnics i tàctics programats i sempre s'acabava amb la realització de combats o pràctica lliure que en la terminologia del judo s'anomenen Randoris. Els continguts que es van impartir es concreten i s'exposen en les taules 6 i 7 (Thabot, 1999; Álamo, 2008).

\begin{tabular}{|c|c|c|c|c|}
\hline \multicolumn{4}{|c|}{ Principis comuns dels esports de lluita } & Tàctica individual \\
\hline \multirow{4}{*}{ 定 } & \multirow{4}{*}{$\begin{array}{l}\text { ABATRE } \\
\text { I } \\
\text { IMMO- } \\
\text { BILITZAR }\end{array}$} & $\begin{array}{l}\text { CREAR } \\
\text { INCERTESA }\end{array}$ & $\begin{array}{l}\text { - Generant informació. } \\
\text { - Ocultant informació. }\end{array}$ & $\begin{array}{l}\text { Lluita per l'agafada i una adequada posició tenint en } \\
\text { compte: } \\
\text { - Diferents maneres d'agafar. } \\
\text { - Desplaçaments. } \\
\text { - Combinacions d'empènyer i tirar. }\end{array}$ \\
\hline & & $\begin{array}{l}\text { CONTROL } \\
\text { DE } \\
\text { L'OPONENT }\end{array}$ & $\begin{array}{l}\text { - Amb continuïtat en les } \\
\text { accions. }\end{array}$ & $\begin{array}{l}\text { - Sense deixar anar els suports sobre l'adversari. } \\
\text { - Combinant desplaçaments i agafades } \\
\text { - Amagant. }\end{array}$ \\
\hline & & DESEQUILIBRAR & $\begin{array}{l}\text { - Identificant les forces que } \\
\text { aplica l'adversari. }\end{array}$ & $\begin{array}{l}\text { - Suprimint els suports de l'adversari sobre nosaltres, } \\
\text { per desviació o ruptura de les forces. }\end{array}$ \\
\hline & & $\begin{array}{l}\text { APLICAR } \\
\text { UNA TĖCNICA }\end{array}$ & - Per abatre i immobilitzar. & $\begin{array}{l}\text { - Aplicar tècniques de segada, escombrada, enganxa- } \\
\text { da, blocatge, amb els braços i les cames. } \\
\text { - Voltejant l'adversari.. } \\
\text { - Utilitzant el pes corporal.. } \\
\text { - Anticipant-nos als moviments de l'adversari.. }\end{array}$ \\
\hline
\end{tabular}

$\Delta$

Taula 6

Continguts de procediment en atac

1 Terminologia referida a les classes de continguts que existeixen en el sistema educatiu. Contreras (1998, p. 170): "El coneixement de qualsevol branca del saber requereix informació que es produeix per mitjà de les dades o fets, que normalment s'aprenen d'una manera memorística i suposen una actitud més passiva per part del subjecte que els aprèn. De manera diferent, els conceptes requereixen un aprenentatge significatiu que necessita una actitud molt més activa envers l'aprenentatge".

2 Els procediments es caracteritzen perquè impliquen "saber fer alguna cosa", suposen una aplicació pràctica. Per a Contreras, el coneixement més significatiu és el referit a les habilitats i destreses de caràcter motriu. 


\begin{tabular}{|c|c|c|c|c|}
\hline \multicolumn{4}{|c|}{ Principis comuns dels esports de lluita } & Tàctica individual \\
\hline \multirow{4}{*}{$\begin{array}{l}\text { 出 } \\
\text { 岀 } \\
\text { 岀 }\end{array}$} & \multirow{4}{*}{$\begin{array}{l}\text { EVITAR LES } \\
\text { ACCIONS DE } \\
\text { L'OPONENT } \\
\text { PER ABATRE } \\
\text { I IMMOBILIT- } \\
\text { ZAR }\end{array}$} & $\begin{array}{l}\text { CREAR } \\
\text { INCERTESA }\end{array}$ & $\begin{array}{l}\text { - Generant informació } \\
\text { - Ocultant informació }\end{array}$ & $\begin{array}{l}\text { Lluita per l'agafada i una adequada posició tenint en } \\
\text { compte: } \\
\text { - Diferents formes d'agafar. } \\
\text { - Desplaçaments. } \\
\text { - Combinacions d'empènyer i tirar. }\end{array}$ \\
\hline & & $\begin{array}{l}\text { OPOSAR-SE AL } \\
\text { CONTROL DE } \\
\text { L'OPONENT }\end{array}$ & $\begin{array}{l}\text { - Evitant la continuïtat en } \\
\text { les accions del l'oponent }\end{array}$ & $\begin{array}{l}\text { - Sense deixar anar els suports sobre l'adversari. } \\
\text { - Combinant desplaçaments i agafades } \\
\text { - Amagant }\end{array}$ \\
\hline & & EQUILIBRAR-SE & $\begin{array}{l}\text { - Cerca de suports en } \\
\text { l'oponent i al terra }\end{array}$ & $\begin{array}{l}\text { - Agafades amb una mà i dues mans. } \\
\text { - Baixant el CDG. }\end{array}$ \\
\hline & & $\begin{array}{l}\text { OPOSAR-SE } \\
\text { A L'APLICACIÓ } \\
\text { TĖCNICA }\end{array}$ & $\begin{array}{l}\text { - Amb tècniques de contra- } \\
\text { atac } \\
\text { - Anticipant-nos als movi- } \\
\text { ments de l'adversari }\end{array}$ & $\begin{array}{l}\text { - Tècniques de segada, escombrada, enganxada, } \\
\text { blocatge, amb els braços i les cames } \\
\text { - Esquivant. } \\
\text { - Sortides de les immobilitzacions per mitjà de la } \\
\text { iniciativa davant de l'error de l'atacant. } \\
\text { - Posant-nos en posició de pronació. } \\
\text { - Atrapant la cama de l'oponent. } \\
\text { - Ampliant la base de sustentació per evitar el volteig. }\end{array}$ \\
\hline
\end{tabular}

Taula 7

Continguts de procediments en defensa

Els models d'ensenyament escollits així com els estils d'ensenyament utilitzats per impartir aquests continguts s'han concretat des de les aportacions de diversos autors (Devís \& Sánchez, 1996; Devís 1996; Méndez, 1999; Jiménez, 2000; Contreras, De la Torre, \& Velázquez, 2001; García, 2001; Contreras, 2007b) i van quedar definits per a la seva aplicació com es reflecteix en la taula 8.

\section{Protocol d'avaluació}

Volem observar el procés de pràctica del judo d'iniciació, és a dir, com fan judo els alumnes i no tan sols com fan caure l'adversari. Les variables observades van ser aquestes: tenir iniciativa en l'acció d'atac, crear incertesa, controlar l'adversari, desequilibrar i, en funció de tot això, les tècniques de projecció realitzades.

El procediment d'observació es va aplicar en finalitzar el període de pràctiques. Es van determinar els enfrontaments aparellant els membres de cada grup, essent la durada de cada combat de tres minuts.

Es comptabilitzaven les accions que realitzaven i que corresponien a cada un dels indicadors de l'avaluació segons s'han definit els continguts impartits en les diferents sessions pràctiques.
Les altres dues proves que van realitzar els alumnes per valorar el coneixement de fets i conceptes eren les següents: una prova en la qual es valoraven els coneixements del reglament després d'haver-los explicat i una altra prova teoricopràctica, en la qual es valoraven la resta de coneixements, inclosos els procedimentals.

\section{Anàlisi estadística}

Es va utilitzar el programa estadístic per Windows SPSS 14.0 i taules Excel 2002 d'elaboració pròpia. En l'estadística existeix un terme equivalent al de comparació i una tècnica associada: contrast d'hipòtesis, que estableix com a supòsits valorar si determinades mostres procedeixen de la mateixa població o no. En el nostre cas, aquell no era exactament el problema, ja que les mostres (grups A, B, C) procedeixen de la mateixa població sotmesa a diferents tractaments (mètodes 1,2 i 3 ).

Una extensió de la tècnica citada es denomina anàlisi de variància (ANOVA I per a un sol factor o tractament). L'experiment realitzat compleix exactament amb els preceptes que requereix aquesta tècnica estadística. També es va estudiar si existien diferències entre els mètodes a l'hora d'assimilar continguts teòrics, pràctics o mixtos. Per a això, es va usar com a tècnica l'ANOVA II amb replicació o análisi factorial, ja que es tractava de dos factors 


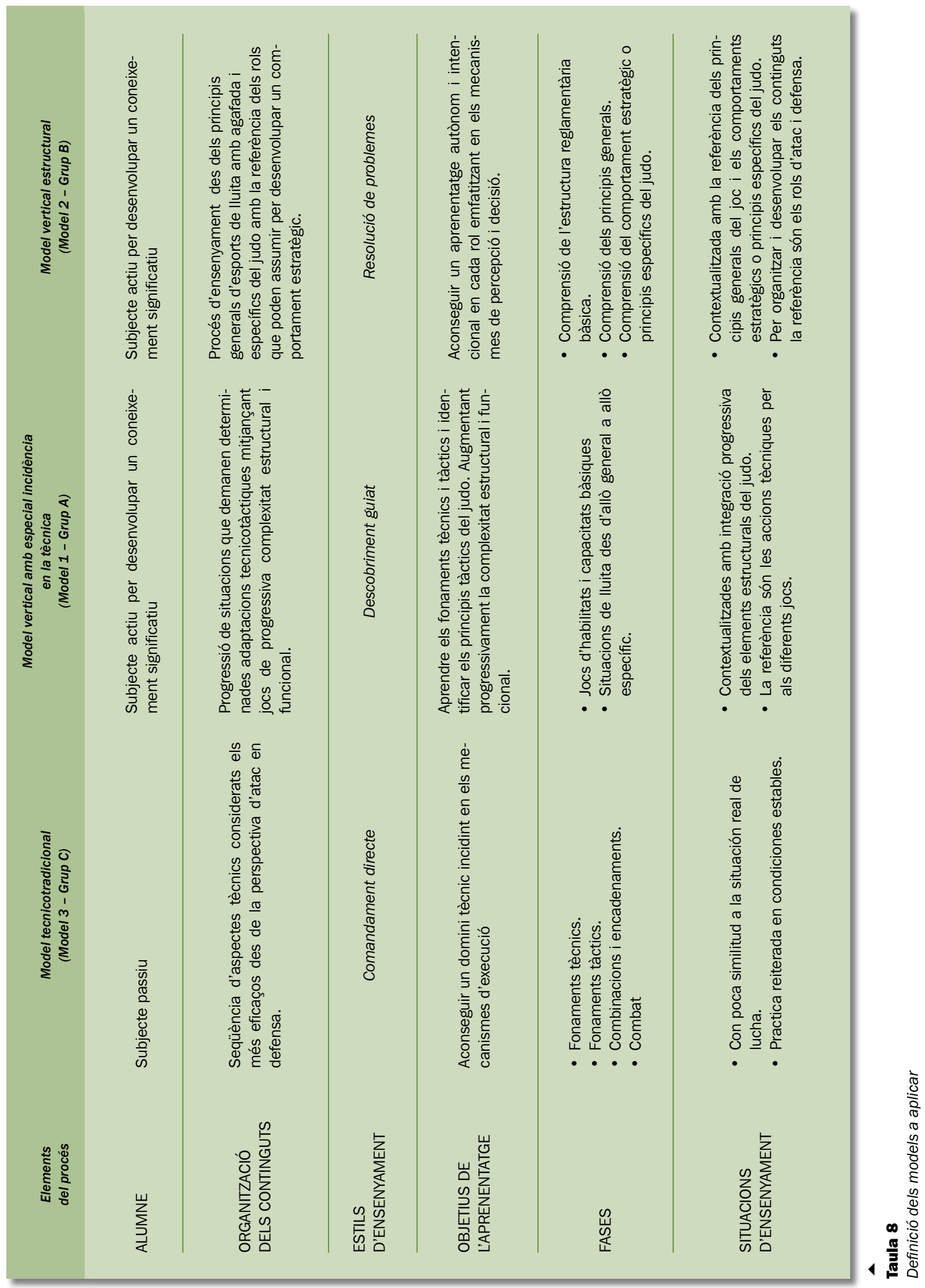


d'estudi (mètodes d'ensenyament i continguts), ${ }^{3}$ cada grup format per una trentena d'alumnes (replicacions).

El desenvolupament seguit per l'estadística en la comparació de mostres podria ajustar-se al que s'ha reflectit en la figura 1.

En la taula 9 s'exposen els dos factors mesurats: mètodes d'ensenyament $\mathrm{i}$ tipus de coneixements; els nivells de cada un dels factors, i el nombre de replicacions que es correspon amb el nombre d'alumnes de cada grup.

\section{Resultats}

La diferència dels respectius valors obtinguts del factor $A$ respecte del valor crític, ${ }^{4}$ és major quan es comparen els models 1 i 2 (taula 11) que quan es comparen els models 1 i 3 (taula 12), i els models 2 i 3 (taula 13). Atès que el que s'està comparant és la diferència de mesures mostrals de les qualificacions obtingudes pels alumnes, major és el grau d'assimilació de coneixements, ja que tots els alumnes van fer el mateix test o prova per avaluar-ne l'aprenentatge. Com hem explicat, la diferència mostral és més gran entre els models 1 i 2 que entre els models 1 i 3 i els models 2 i 3 , tot i que no sabem si aquesta diferència és a favor o en contra, és a dir, si la mitjana del model 1 és més gran que la del 2 i la del 3.

És necessària una altra dada que pugui discernir aquesta qüestió. Per aquest motiu es van realitzar les estimacions dels intervals de confiança de cada mitjana mostral. Se'n van obtenir els següents valors:

- Model 1: [4,33, 6,22 ].

- Model 2: [4,04, 6,46].

- Model 3: [ 3,96, 6,35 ].

\begin{tabular}{ccc|} 
Factor & Comparativa & \multicolumn{1}{c|}{$\begin{array}{c}\text { Conclusions estadístiques } \\
\text { No existeixen diferències sig- }\end{array}$} \\
\hline A & $\mathbf{0 , 0 1}<\mathbf{2 , 9 9}$ & $\begin{array}{l}\text { nificatives entre els models } \\
\text { d'ensenyament impartits. }\end{array}$ \\
\hline Taula 10 & & \\
\hline Factor & Comparativa & Conclusions estadístiques \\
\hline A & $\mathbf{0 , 0 0 5 3 < 3 , 9 4}$ & $\begin{array}{l}\text { No existeixen diferències signi- } \\
\text { ficatives entre els models } 1 \mathrm{i} 2 .\end{array}$ \\
\hline
\end{tabular}

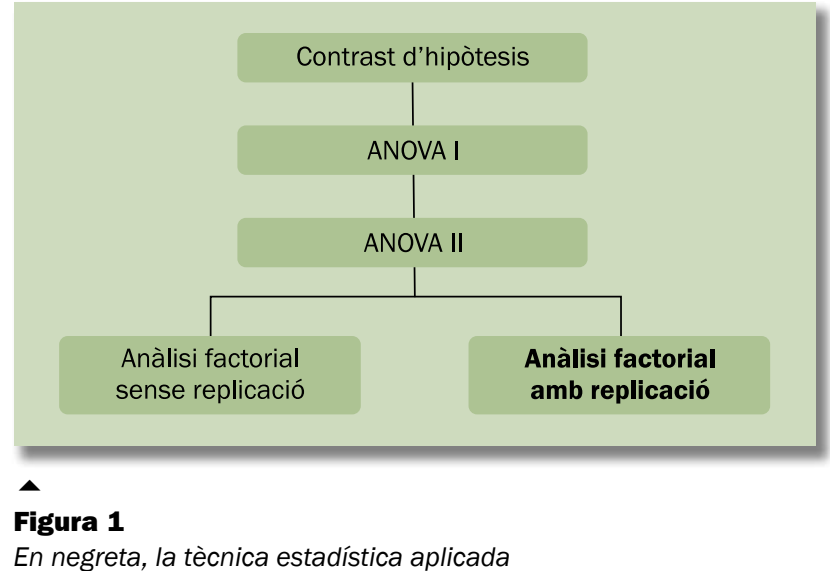

En negreta, la tècnica estadística aplicada

\begin{tabular}{|c|c|c|}
\hline Factors & Nivels & Replicacions \\
\hline \multirow{3}{*}{$\begin{array}{l}\text { Factor A } \\
\text { Mètodes } \\
\text { d'ensenyament }\end{array}$} & Model 1: grup A & $n 1=38$ \\
\hline & Model 2: grup B & $n 2=34$ \\
\hline & Model 3: grup C & $n 3=34$ \\
\hline \multirow{3}{*}{$\begin{array}{l}\text { Factor B } \\
\text { Tipus de conei- } \\
\text { xements } \\
\text { (continguts) }\end{array}$} & Teòrica: $1 \mathrm{P}$ & \\
\hline & Teòrica-pràctica: $2 \mathrm{P}$ & \\
\hline & Pràctica: Randori & \\
\hline
\end{tabular}

\section{Taula 9}

Factors, nivells y replicacions per a l'anàlisi estadística

Segons aquestes dades, sembla lògic pensar que la diferència de mostres respecte del model 1 sempre és a favor d'aquest, és a dir, és el model del qual s'obtenen més qualificacions. Això indica que el model 1 és l'òptim. En la mateixa línia de raonament, podem afirmar que els valors de mesures mostrals s'escurçaran quan es comparin els models 2 i 3 . Però, qui d'ells és més efectiu, en termes i qualificacions obtingudes?

La comparació dels models 1 i 3 ens dóna la resposta, ja que el valor de diferència de les seves mitjanes,

\begin{tabular}{ccc|} 
Factor & Comparativa & \multicolumn{1}{c|}{ Conclusions estadístiques } \\
\hline A & $\mathbf{0 , 0 2}<\mathbf{3 , 9 4}$ & $\begin{array}{l}\text { No existeixen diferències signi- } \\
\text { ficatives entre els models } 1 \mathrm{i} 3 .\end{array}$ \\
\hline $\begin{array}{c}\text { Taula } 12 \\
\text { Factor }\end{array}$ & Comparativa & Conclusions estadístiques \\
\hline A & $\mathbf{0 , 0 0 2 9}<\mathbf{3 , 9 4}$ & $\begin{array}{l}\text { No existeixen diferències signi- } \\
\text { ficatives entre els models 2 i 3. }\end{array}$ \\
\hline
\end{tabular}

\footnotetext{
3 En aquest article s'ometrà tot allò referent a dades i conclusions de l'anomenat factor 2: continguts.

4 És el valor a partir del qual es rebutja la hipòtesi $H o$. En el nostre cas, $F_{\alpha, g 11, g 12}=3,94$.
} 
$(0,02)$ és inferior al de comparació entre 1 i $2(0,0053)$. Això significa que el model 3 s'aproxima més al model 1 del que ho fa el model 2 .

Tot això suposa que podem expressar-nos de la següent manera:

1. El model òptim d'aprenentatge sembla que és el model 1.

2. El model menys efectiu en termes d'aprenentatge sembla que és el model 3.

Si establim un rànquing de major a menor efectivitat en l'ensenyament seria:

- Model 1.

- Model 2.

- Model 3.

\section{Discussió i conclusions}

El treball d'aplicació per comparar diferents models d'ensenyament en la iniciació, de manera general, no ha estat una de les prioritats com a tema d'investigació en l'educació física i esportiva. Méndez (1999) cita, en la seva anàlisi, els treballs fets en esports com ara el bàsquet i el voleibol, l'hoquei sala, el futbol, el bàdminton i el tennis.

Treballs com el de Valero, Conde, Delgado i Conde (2006), en atletisme; Bovi, Palomino i González (2008), en natació; López i Castejón (2005), citen els treballs empírics de French, Werner, Rink, Taylor, i Hussey (1996); García (2001) i Aguado, Castejón i De la Calle (2002), en esports com l'handbol i el bàsquet són alguns exemples concrets. En esports del grup del judo, un estudi empíric comparatiu és el de Guerra (2002) en lluita canària.

Méndez (1999) analitza les investigacions que s'han desenvolupat especificant les variables considerades, que en són tres: el desenvolupament del coneixement, el desenvolupament de les tècniques esportives i l'aprenentatge desenvolupat referit als components del joc (control, presa de decisió -component tàctic- i execució). Són setze investigacions publicades que van comparar dos models d'ensenyament: el tradicional o tècnic i el model alternatiu o tàctic. Dels resultats obtinguts es conclou que la majoria dels estudis no han verificat diferències significatives entre els grups quant al grau de coneixement adquirit per l'alumnat en treballs desenvolupats en un interval d'entre sis i deu sessions. En treballs d'investigació amb una duració de quinze sessions, es poden observar diferències a favor del grup d'alumnes que aprenen amb el model tàctic.

Els resultats que hem obtingut en el nostre treball respecte al nivell de coneixement que han adquirit els alumnes i les alumnes, evidencien que amb els tres tipus de continguts en el model vertical amb referència a la tècnica (model tecnicotàctic) i l'estil de descobriment guiat és el de major efectivitat.

Respecte de la presa de decisions durant el joc o el que nosaltres expressem com el procés, els resultats més favorables també s'obtenen amb el model tàctic. Ens referim a esports d'invasió o d'equip i que en tots els casos no es va considerar el procés de presa de decisions dels diferents rols que poden assumir els jugadors (Méndez, 1999).

Un altre estudi és el de Romero (2000), que desenvolupa l'aplicació de dos models d'ensenyament, un de tècnic i un altre de comprensiu (tàctic) en la iniciació al voleibol. Els resultats d'aquest estudi en escoles municipals demostren que els alumnes que van aprendre amb el model comprensiu han obtingut més progressos en els aprenentatges que els del model tècnic o tradicional.

En esports de lluita, Guerra (2002) és l'autor que ens presenta un primer treball d'investigació comparativa entre dos models d'ensenyament. Un d'ells és el model tradicional, amb un ensenyament directiu i basat en la reproducció de models tècnics d'execució. L'altre consisteix en un ensenyament basat en la indagació i amb subrols luctatoris (si la denominació de la tècnica és 0 -soto-gari, el subrol és "segar amb la cama"). Aquest segon model implica la metodologia i els continguts d'ensenyament amb un tractament dels continguts estratègics des de la perspectiva de l'anàlisi de la lògica de les situacions motrius. Es tracta, en definitiva, de determinar els efectes sobre l'aprenentatge de les dues metodologies d'ensenyament, un basat en els subrols específics i l'altre, en els models tècnics de lluita canària.

Els resultats d'aquest estudi, evidencien que independentment de la metodologia utilitzada i del tipus de continguts impartits, els dos grups d'alumnes van incrementar els resultats en les proves d'avaluació tècnica. Quant al segon objectiu de la investigació, Guerra (2002) exposa que el comportament estratègic del grup que va desenvolupar el procés d'aprenentatge amb el mètode de la cerca i el descobriment de solucions motrius va obtenir millors resultats. Concretament, els valors van ser un increment de 6,1 subrols executats enfront de 3,5. 
Com una de les conclusions, l'autor exposa que la metodologia d'ensenyament amb tasques semidefinides, models d'execució semioberts, i amb continguts tècnics amb orientació estratègica sembla aportar un aprenentatge superior al model amb tasques definides, models d'execució tancats i continguts exclusivament tècnics.

Amb els resultats del nostre treball, també podem afirmar que el model vertical amb referència a la tècnica i el descobriment guiat és el model més eficient quant als resultats en l'aprenentatge dels alumnes.

La investigació per comparar models d'ensenyament no està unificada. En alguns casos es comparen dos models i en uns altres, tres, com és el cas d'aquest treball. Les diferències fonamentals entre uns models $i$ altres són establir un procés analític, mecanicista i amb un estil d'ensenyament directiu per part de l'educadorentrenador, com és el cas del model tecnicotradicional; o l'altra opció que és establir un procés d'ensenyament amb l'alumne o alumna amb subjecte actiu utilitzant un estil d'ensenyament des de la indagació i el descobriment.

Per tot el que s'ha exposat en aquest treball, els models d'ensenyament que proposen situacions que propicien el descobriment i la indagació dels alumnes són els més efectius per a l'adquisició de coneixements. Tanmateix, cal considerar l'esport escollit; el nivell dels alumnes que participen en la investigació; el nombre de sessions en què s'ha establert; els models d'ensenyament escollits; les variables, i la manera de mesurar-les.

\section{Referències}

Aguado, R., Castejón, F. J., \& De la Calle, M. (2002). La enseñanza del deporte con diferentes estrategias de enseñanza: técnica, táctica y técnico- táctica. Revista de Educación Física. Renovar la teoría y la práctica (86), 27-33.

Álamo, J. M. (2008). La iniciación al judo en la educación física escolar. Sevilla: Wanceulen.

Aranceta, J., Pérez, C., Ribas, L., \& Serra, L. (2005). Epidemiología y factores determinantes de la obesidad infantil y juvenil en España. Revista de Pediatría de Atención Primaria, 7(Supl. 1), 13-20.

Bovi, F., Palomino, A., \& González, J. J. (2008). Avaluació i contrast dels mètodes d'ensenyament tradicional i lúdic. Apunts. Educació Física i Esports (94), 29-36.

Cecchini-Estrada, J. A., Echevarría, L. M., \& Méndez, A. (2003). Intensidad de la motivación hacia el deporte en la edad escolar. Universidad de Oviedo: Vicerrectorado de Extensión Universitaria.

Cecchini, J. A., Méndez, A., \& Contreras, O. R. (2005). Motivos de abandono de la práctica del deporte juvenil. Cuenca: Ediciones de la Universidad de Castilla - La Mancha.

Contreras, O. R. (1998). Didáctica de la educación física. Un enfoque constructivista. Barcelona: Inde.
Contreras, O. R. (2007a). El problema de la obesidad infantil. Intervención didáctica en educación física. A N. Mendoza, Condición física, habilidades deportiva y calidad de vida (pàg. 9-29). Madrid: Ministerio de Educación y Ciencia.

Contreras, O. R. (2007b). Los modelos de enseñanza para la iniciación deportiva: estado de la cuestión. Curs d'Iniciación deportiva municipal. 1 i 2 de juny. Las Palmas de Gran Canaria. Cabildo de Gran Canaria. Apunts inèdits.

Contreras, O. R., De la Torre, E., \& Velázquez, R. (2001). Iniciación deportiva. Madrid: Editorial Síntesis.

Devís, J. \& Sánchez, R. (1996). La enseñanza alternativa de los juegos deportivos: antecedentes, modelos actuales de iniciación y reflexiones finales. A J. A. Moreno \& P. L. Rodríguez (Eds.), Aprendizaje deportivo (pàg. 159-181). Universidad de Murcia.

Devís, J. (1996). Educación física, deporte y currículum. Investigación y desarrollo currricular. Madrid: Visor.

Hernández, J. L. \& Martínez, M. E. (2007). Estilo de vida y frecuencia de práctica de actividad física de la población escolar. A J. L. Hernández \& R. Velázquez (Coords.), La educación física, los estilos de vida y los adolescentes: cómo son, cómo se ven, qué saben y qué opinan. (pàg. 89-114). Barcelona: Graó.

French, K. E., Werner, P. H., Rink, J. E., Taylor, K., \& Hussey, K. (1996). The effects of 3-week unit of tactical, skill, or combined tactical and skill instruction on badminton performance on ninth-grade students. Journal of Teaching in Physical Education, 15(4), 418-438.

García, L. M. (2001). Hacia una clasificación actualizada y unificada de los modelos alternativos de enseñanza en la iniciación deportiva. Docencia e investigación: revista de la Escuela de Magisterio de Toledo, 26(11), 31- 42.

Guerra, G. (2002). Análisis comparado de dos metodologías de enseñanza de la técnica en los juegos deportivos: una aplicación en la lucha canaria (Tesi doctoral). Departamento de Educación Física, Universidad de Las Palmas de Gran Canaria.

Jiménez, F. (2000). Estudio praxiológico de la estructura de las situaciones de enseñanza en los deportes de cooperación / oposición de espacio común y participación simultánea: balonmano y fútbol sala (Tesi doctoral). Departamento de Educación Física, Universidad de Las Palmas de Gran Canaria.

López, V. \& Castejón, F. J. (2005). L'ensenyament integrat tecnicotàctic dels esports en edat escolar Explicació i bases d'un model. Apunts. Educació Física i Esports (79), 40-48.

Martín-Albo, J. \& Núñez, J. L. (1999). Las motivaciones deportivas ¿Cuestión de tiempo? Revista de Psicología del Deporte, 8(2), 283-293.

Méndez, A. (Marzo 1999). Modelos de enseñanza deportiva. Análisis de dos décadas de investigación. Lecturas: Educación Física y Deportes, 4(13). Recuperat de http://www.efdeportes.com/efd13/amendez.htm

Monteagudo, M. J. (2000). El deporte escolar durante la infancia: claves para la gestión de preferencias y adquisición de hábitos deportivos. A C. Maiztegui \& V. Pereda (Coords.), Ocio y deporte escolar. Universidad de Deusto: Bilbao.

Romero, S. (2000). Reflexiones conceptuales de iniciación deportiva escolar y estudio de dos enfoques metodológicos. Treball presentat a I Congreso Nacional de Deporte en edad escolar (pàg. 81-109). Dos Hermanas, Sevilla: Patronato Municipal de Deportes.

Serra, L., Ribas, L., Aranceta, J., Pérez, C., Saavedra, P., \& Peña, L. (2003). Obesidad infantil y juvenil en España. Resultados del Estudio enKid (1998-2000). Medicina Clínica, 121(19), 725-732.

Thabot, D. (1999). Judo óptimo. Análisis y metodología. Barcelona: Inde.

Valero, A., Conde, A., Delgado, M., \& Conde, J. L. (2006). Incidència dels enfocaments d'ensenyament tradicional i ludotècnic sobre les variables relacionades amb el procés d'ensenyament-aprenentatge en la iniciació a l'atletisme. Apunts. Educació Física i Esports (84), 32-38. 